\title{
Mediators of Inflammation as a Link Between Diabetes Mellitus and Periodontal Breakdown
}

\begin{abstract}
Adriana Monea, Lia Yero Eremie*, Csilla Bukhari, Gabriela Beresescu, Carmen Biris
University of medicine and pharmacy Tirgu-Mures, Romania

Our objective was to investigate immunological changes that occur in saliva of subjects with type 2 diabetes mellitus (T2DM) without signs of periodontal disease and to establish if salivary inflammatory cytokines are a possible link between diabetes mellitus and periodontal breakdown. Material and methods. Twenty T2DM subjects with no periodontal disease and twenty healthy controls were registered for the present study. TNF- $\alpha$ and IL-6 level from saliva and serum were measured. Periodontal tissue samples were histologically examined. Results: TNF- $\alpha$ and IL-6 levels were higher in T2DM subjects compared to controls, with an extremely significant difference in saliva ( $<<0.001$ ). Significant inflammation, affecting both epithelial and connective tissues was present in periodontal biopsies. Conclusions: The subjects showed an increased TNF- $\alpha$ and IL-6 levels, both in serum and -mostly in -saliva of diabetics without signs of periodontal disease, confirming the hypothesis of immunological implication, as a correlation between periodontal disease incidence and diabetes mellitus. Histologic alterations, suggesting a local inflammatory state, were present in periodontal tissue of diabetics, confirming the above hypothesis. The study reveals that saliva analysis is a quite efficient method in testing the periodontal breakdown progression in the subjects with T2DM.
\end{abstract}

Keywords: diabetes mellitus, periodontal disease, TNF- $\alpha$, II-6, histopathology

Received 11 January 2018 / Accepted 29 January 2018

\section{Introduction}

Diabetes mellitus is a heterogeneous group of metabolic disorders that have in common hyperglycemia, beeing a worldwide major health concern, as the number of cases of both types of diabetes are constantly increasing. Chronic hyperglycemia is associated with irreversible complications such as nephropathy, retinopathy, neuropathy,cardiovascular diseases, peripheral vascular diseases,delayed healing and periodontal diseases [1]. It is still not completely understood the exact mechanism by which diabetes affects periodontal tissues [2, 3].

The aim of this study was to investigate immunological changes that occur in the saliva of subjects with type 2 diabetes mellitus without clinical signs of periodontal disease and the influence of these changes on periodontal tissues. We evaluated as well if salivary inflammatory cytokines are a possible link between diabetes mellitus and periodontal tissue alteration, and if salivary cytokines can play the role of an indicator in the progression of periodontal disease.

\section{Material and methods}

The study group included 20 type 2 diabetic subjects without any clinical signs of established periodontal disease. Twenty systemically healthy subjects served as controls. Diabetics were recruited from the Puls Health Center Tg. Mures, without the knowledge of the patients` glycaemic control level and they were chosen to participate in the study after a periodontal examination. The systematically healthy control group was recruited after a general dental examination, followed by a periodontal examination; they were chosen from the patients of the Odontology and Oral Pathology Department of UMF Tg Mures.

Inclusion criteria for the control group were as follow: $\geq 20$ years of age; at least 20 periodontally healthy teeth; no attacment level $>2$ and no probing pocket depth $>$ $3 \mathrm{~mm}$. The subjects with Type 2 daiabetes were at least 20 years old, had a minimum of 20 teeth; no major diabetic complications; no periodontal changes; during the last six months without antibiotic, corticoid or immunosuppressive treatment in the medical history. Smokers, subjects who had medical conditions that would require antibiotic prophylaxis for routine dental procedures or influence the course of diabetes treatment were excluded from the study.

Clinical examination had the following procedure: information regarding the personal data of the subjects, contouring the medical history, extra- and intraoral examination. A trained clinician measured the following periodontal parameters at 6 sites per tooth (mesiolingual, lingual and distolingual, mesiobuccal, buccal, distobuccal), for all present teeth, third molars being excluded. Clinical parameters included: visible plaque accumulation ( 0 or 1$)$, gingival redness ( 0 or 1$)$, bleeding on probing ( 0 or 1$)$, recession $(\mathrm{mm})$ and poket depth $(\mathrm{mm})$. The values were rounded to the nearest upper $\mathrm{mm}$.

Ethical Comity of UMF Tg. Mures approved the procedure of the study as well. An informed consent was signed by the participants after a previous information about the purpose of the study.

For the detection of TNF- $\alpha$ and IL- 6 in both saliva and serum, we used the same method as described in one of our previous studies [4]. Two ml of unstimulated saliva and 
venous blood were collected from each enrolled subject, than centrifugated, the supernatant filtered and refrigerated until examination. ELISA-sandwich method was used to determine the TNF- $\alpha$ levels both in saliva and serum. For this purpose it was chosen an easily accessible immunoassay kit (OptEIA human TNF- $\alpha$, Pharmingen, USA). Manufacturer`s guidelines were strictly respected. TNF- $\alpha$ levels from both the saliva and serum were compared trough extrapolation with TNF- $\alpha$ standard, given in $\mathrm{pg} /$ $\mathrm{ml}$. Detection of salivary and serum IL-6 levels were performed using an easily accessible enzyme-linked immunoabsorbent, sandwich ELISA test (DuoSet ELISA Development System, R\&D Systems, USA), again manufacturer`s guidelines were severely respected. Results were given as total amount of IL-6 in $\mathrm{pg} / \mathrm{ml}$.

In case of each diabetic subject blood glucose and glycated haemoglobin ( $\mathrm{HbA1}$ ) levels were determined with the purpose to detect their glycaemic control level.

For the statistical analysis of the data it was used the Mann-Whitney nonparametric test in order to determine if there are any statistically significant differences between salivary and serum levels of TNF- $\alpha$ and Il-6 in diabetics versus controls. Only p values over 0.05 were considered statistically significant.

From each diabetic subject, biopsy specimens were obtained from a dental-periodontal unit in the posterior region of dental arches and sent for histopathology study. Histopathological examination was performed using formalin fixed, paraffin embedded tissue fragments following standard protocols. The specimens were sliced in 4-5 micron thick tissue sections, stained with hematoxylin-eosin and digitally examined using Zeiss MiraxScan system.

\section{Results}

The diabetic subjects enrolled in the study had a mean age of $46.73 \pm 7.38$, records of at least 5 years of diagnosed Type 2 diabetes, and each of them showed oral antidiabetic drug treatment in the medical history.. Detection of HbAlc and blood glucose levels showed medium to poor glycaemic control in all enrolled diabetics, and and first degree obesity was evident in some of the patients, with a mean value of BMI around 27.95 (table 1). Biologic and clinical parameters of all subjects are presented in table 1.

Serum IL-6 levels in type 2 diabetics were significantly increased $(p<0.001)$ compared to healthy controls (figure 1). Serum TNF- $\alpha$ levels in diabetics were higher than in healthy controls, without statistical relevance $(\mathrm{p}=0.465)$ (figure 2).

Both TNF- $\alpha$ and IL-6 levels showed a significant increase in the saliva of diabetic patients compared with the control group ( $\mathrm{p}<0.0001)$ (figure 3 and 4).

Data concerning the correlation between serum and salivary levels of both cytokines and other clinical parameters in diabetic subjects are presented in table 2. No significant correlation was established, as p-value was higher than 0.05 .
Table 1. Demographic, biologic and clinical parameters of subjects in the study groups

\begin{tabular}{lcc}
\hline & $\begin{array}{c}\text { T2DM }(n=20) \\
\text { Mean } \pm \text { Std.dev. }\end{array}$ & $\begin{array}{c}\text { Controls }(n=20) \\
\text { Mean } \pm \text { Std.dev. }\end{array}$ \\
\hline Age (years) & $46.73 \pm 7.38$ & $43.09 \pm 14.10$ \\
$\%$ males & 40 & 38 \\
BMl & $27.95 \pm 2.38$ & $25.06 \pm 4.74$ \\
Glycaemia $(\mathrm{mg} / \mathrm{dL})$ & $168.46 \pm 21.63$ & $82.61 \pm 15.65$ \\
HbA1C $(\%)$ & $9.02 \pm 0.84$ & - \\
Pocket depth $(\mathrm{mm})$ & $2.74 \pm 0.12$ & $1.82 \pm 0.24$ \\
Recession $(\mathrm{mm})$ & $0.14 \pm 0.15$ & $0.11 \pm 0.11$ \\
$\%$ sites with: & & \\
plaque & $20 \pm 3$ & $22 \pm 18$ \\
bleeding on probing & $13 \pm 6$ & $10 \pm 8$ \\
gingival redness & $5 \pm 2$ & $3 \pm 5$ \\
\hline
\end{tabular}

Table 2. Correlations between serum and salivary cytokines levels and biologic parameters in diabetic patients.

\begin{tabular}{lccc}
\hline Correlation between & Cases & $\begin{array}{c}\text { Correlation } \\
\text { coefficient }\end{array}$ & p-value \\
\hline Serum IL-6 level and age & 20 & 0.491 & 0.063 \\
Serum IL-6 level and BMI & 20 & 0.084 & 0.766 \\
Serum IL-6 level and glycaemia & 20 & 0.098 & 0.727 \\
Serum IL-6 level and HbA1C & 20 & 0.219 & 0.433 \\
Serum IL-6 and serum TNF level & 20 & 0.345 & 0.208 \\
Serum and salivary IL-6 level & 20 & 0.500 & 0.057 \\
Salivary IL-6 level and age & 20 & -0.296 & 0.284 \\
Salivary IL-6 level and BMI & 20 & 0.456 & 0.087 \\
Salivary IL-6 level and glycaemia & 20 & 0.465 & 0.081 \\
Salivary IL-6 level and HbA1c & 20 & 0.504 & 0.056 \\
Serum TNF- $\alpha$ level and age & 20 & 0.363 & 0.183 \\
Serum TNF- $\alpha$ level and BMI & 20 & -0.167 & 0.553 \\
Serum TNF- $\alpha$ level and glycaemia & 20 & -0.095 & 0.737 \\
Serum TNF- $\alpha$ level and HbA1C & 20 & 0.215 & 0.443 \\
Serum and salivary TNF- $\alpha$ levels & 20 & 0.674 & 0.006 \\
Serum TNF- $\alpha$ and salivary IL-6 levels & 20 & 0.345 & 0.208 \\
Salivary TNF- $\alpha$ level and age & 20 & 0.409 & 0.130 \\
Salivary TNF- $\alpha$ level and BMI & 20 & -0.376 & 0.168 \\
Salivary TNF- $\alpha$ level and glycaemia & 20 & 0.070 & 0.805 \\
Salivary TNF- $\alpha$ level and HbA1C & 20 & 0.106 & 0.708 \\
Salivary TNF- $\alpha$ and IL-6 levels & 20 & -0.100 & 0.723 \\
\hline
\end{tabular}

Histological alterations in tissue sections obtained from diabetic patients were present in both the epithelium and the lamina propria of gingival tissue. Acanthosis and parakeratosis were noticed at epithelial level, with reduced quantities of acute inflammatory infiltrate composed mostly of polymorphonuclear leucocytes (segmented granulocytes) throughout its thickness and in superficially located microabscesses. A diffuse polymorphous inflammatory infiltrate consisting of lymphocytes, plasma cells and, to a lesser extent, granulocytes was present in the mildly fibrotic lamina propria, displacing collagen fibers and surrounding ectatic blood vessels and exteriorized erythrocytes (figure 5 and 6). Biopsies showed mitotic activity in the basal layer of 


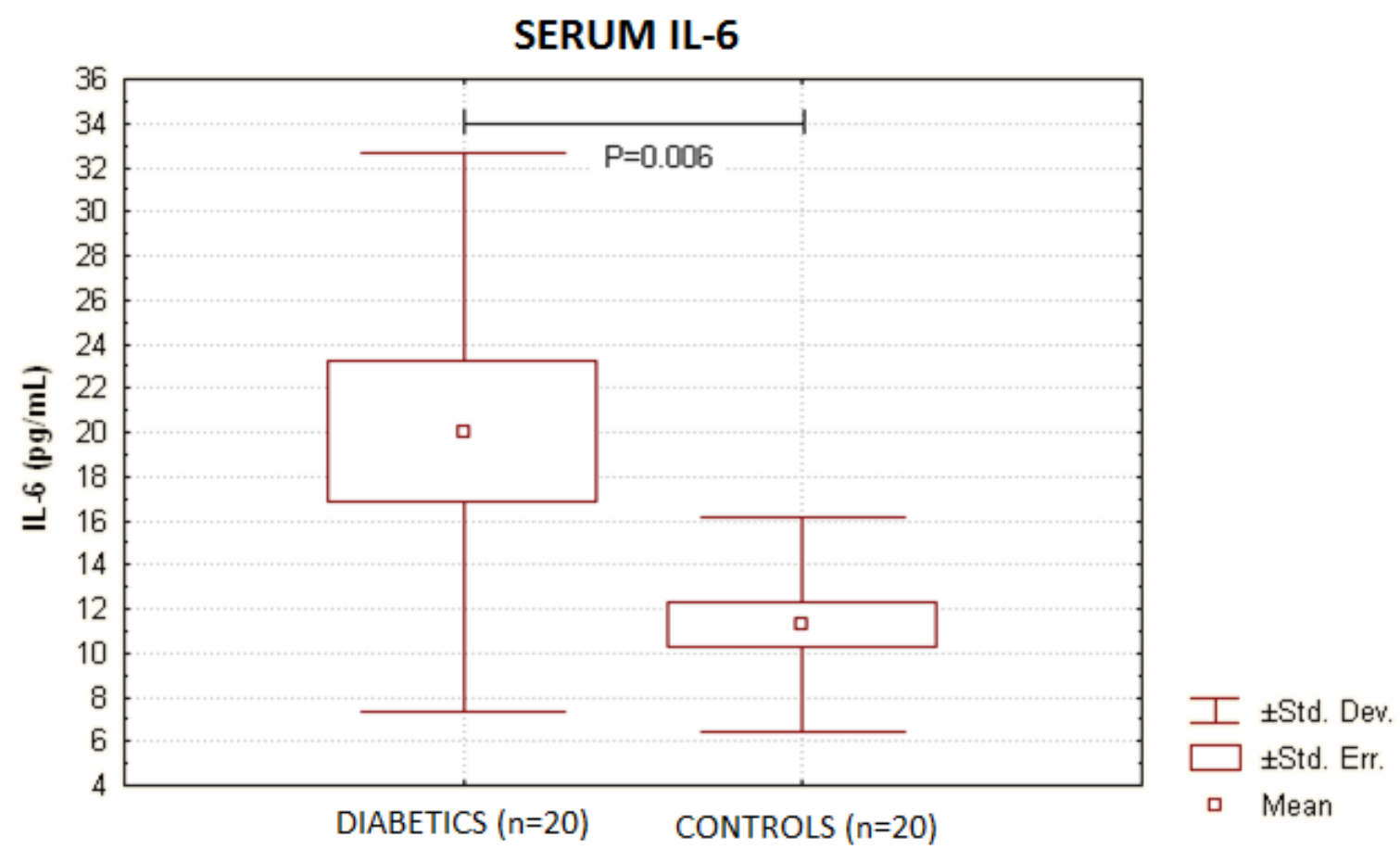

Fig. 1. Serum IL-6 in study groups

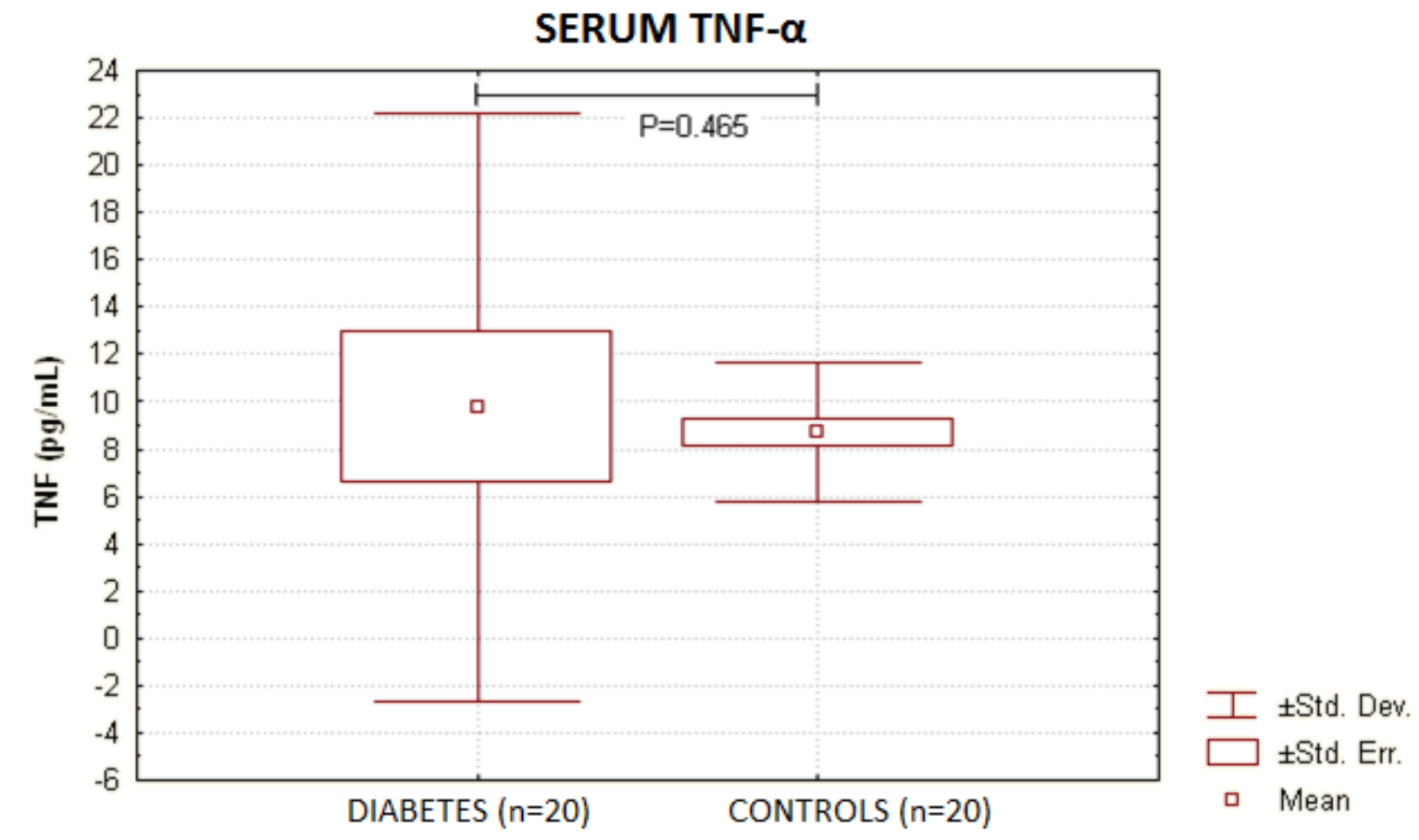

Fig. 2. Serum TNF- $\alpha$ in study groups

the epithelium that accompanies the inflammatory process. Stratum spinosum presented several cellular intra-epithelial vacuolization and acantholysis. In lamina propria a perivascular lymphoplasmocitic infiltrate surrounded dilated capillaries and venules. The connective tissue was degraded due to a rich inflammatory infiltrate and fibrosis.

\section{Discussions}

The hypothesis of the study was that diabetes mellitus can increase salivary TNF- $\alpha$ and IL- levels, contributing to periodontal breakdown. The serum of diabetic subjects showed elevated TNF- $\alpha$ and IL- 6 levels versus the healthy control group, but very high differences of these cytokines were noticed in the saliva of diabetics. Sevaral studies on salivary TNF- $\alpha$ levels did not provide any evidence of association with periodontal disease, because salivary TNF- $\alpha$ levels are very low or nonexistent [5-11]; only few studies reported significantly elevated salivary TNF- $\alpha$ levels in subjects with periodontitis as compared to healthy controls, but the levels of TNF- $\alpha$ were very low $(<4.3 \mathrm{pg} / \mathrm{mL})$ [12]. 
SALIVARY IL-6

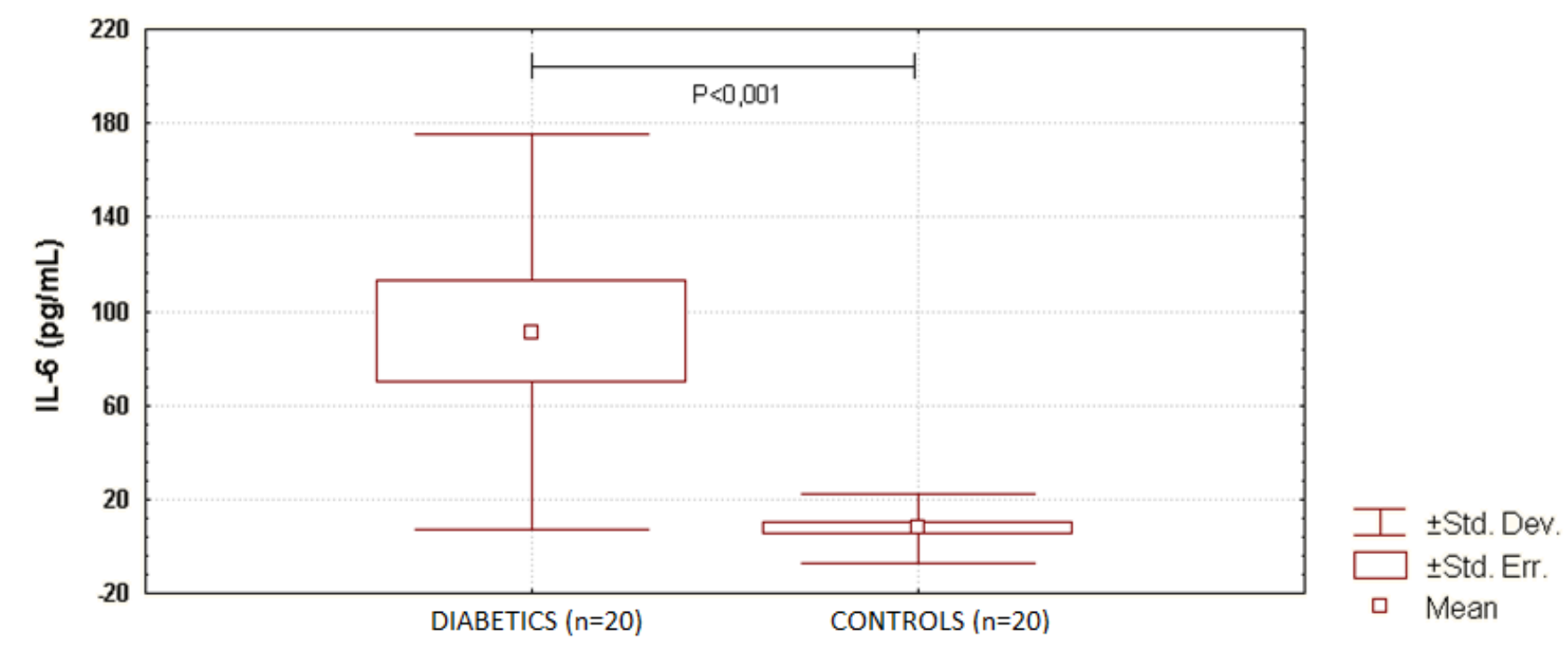

Fig. 3. Salivary IL-6 in study groups

SALIVARY TNF- $\alpha$

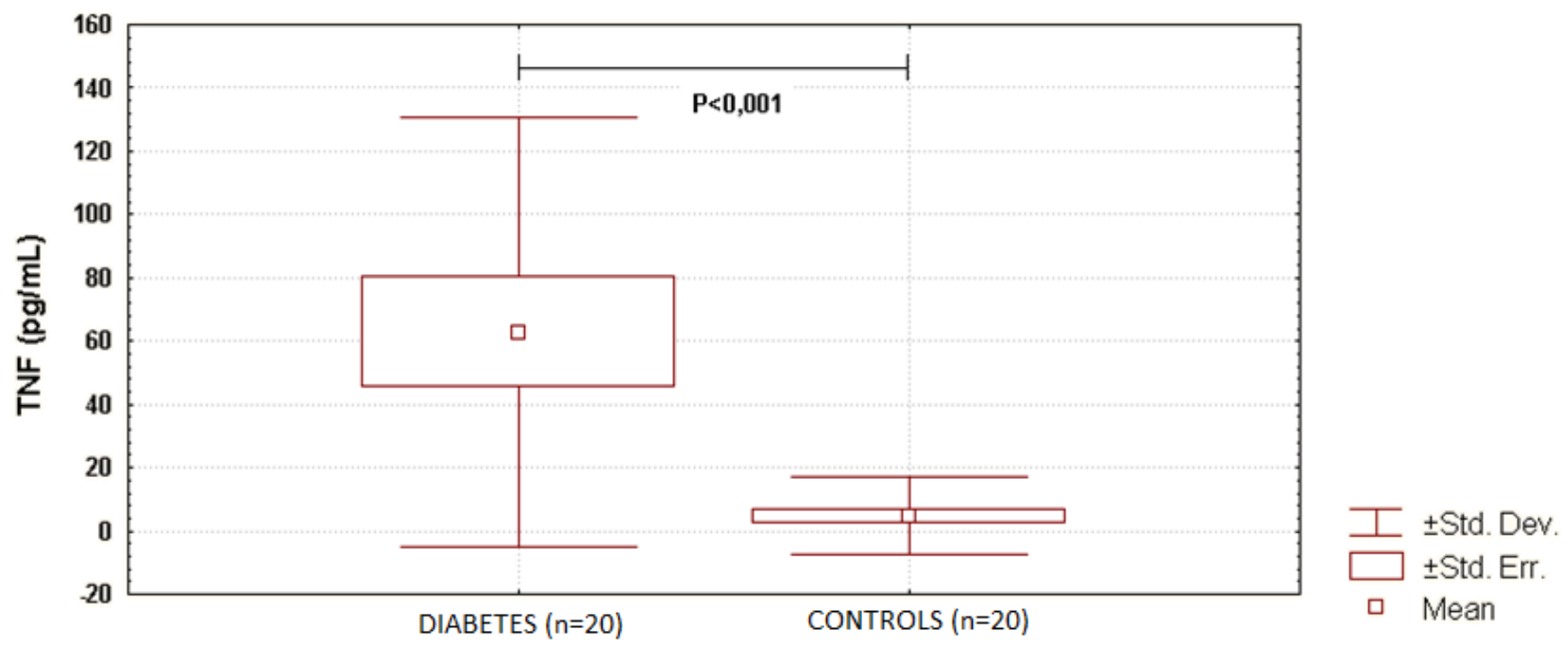

Fig. 4. Salivary TNF- $\alpha$ in study groups

Most of the studies on salivary IL-6 showed no association with periodontal disease $[5,7,9,10]$. Opposite, in 3 reports significantly elevated salivary IL-6 levels were found in subjects with periodontitis $[8,13,14]$. The detected salivary TNF- $\alpha$ and IL- 6 concentrations were significantly increased compared with both the control group of our own study and the mean TNF- $\alpha$ and IL- 6 values described by others in systematically healthy subjects and almost equal to mean levels in systematically healthy parodontopatic patients [15-17]. This confirms the hypothesis of the present study, that diabetes mellitus might co-induce the onset, progression and prognosis of periodontal disease.

In our study salivary IL- 6 showed a tendecy to be similar with HbA1c and blood glucose levels, but results are not powerful because of the small amount of study group. Thus, we may postulate that detection of IL-6 level in total saliva might be enough to evaluate the progression of peri- odontal disease in case of the patients who present type 2 diabetes mellitus.

Saliva, or more appropriate „oral liquid”, is consisted of exocrine secretions of the oral salivary glands, gingival crevicular fluid, as well as elements from dental plaque and diet $[18,19]$. It is already known that saliva might be a source for identifying useful biomarkers, as well as for developing convenient technologies to measure these in the clinic and (potentially) at home [20, 21]. The abundant amount of this liquid, its cheep collection method and its accessibility through noninvasive and painless procedures make clinical trial involvement more attractive for the patient. Also, it does not require specially trained medical or dental staff for collection. Different markers at low levels can be detected in saliva, although some salivary proteins that are in high quantities (e.g. albumin, immunoglobulins) may interfere with the detection of less abundant proteins [22] 


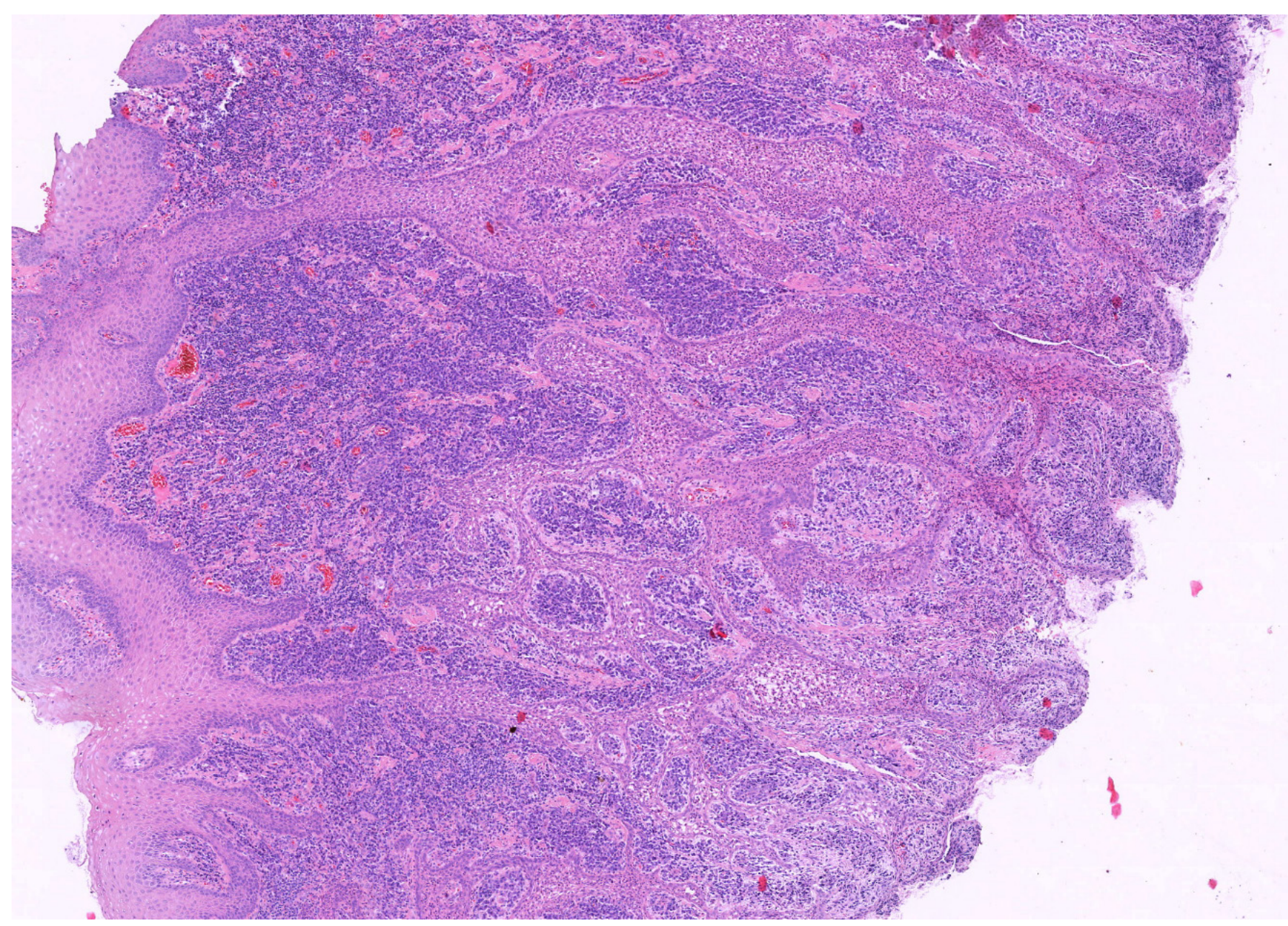

Fig. 5. Histological alterations present in both the epithelium and the lamina propria (gingival biopsy from diabetic, HE stain, 10x)

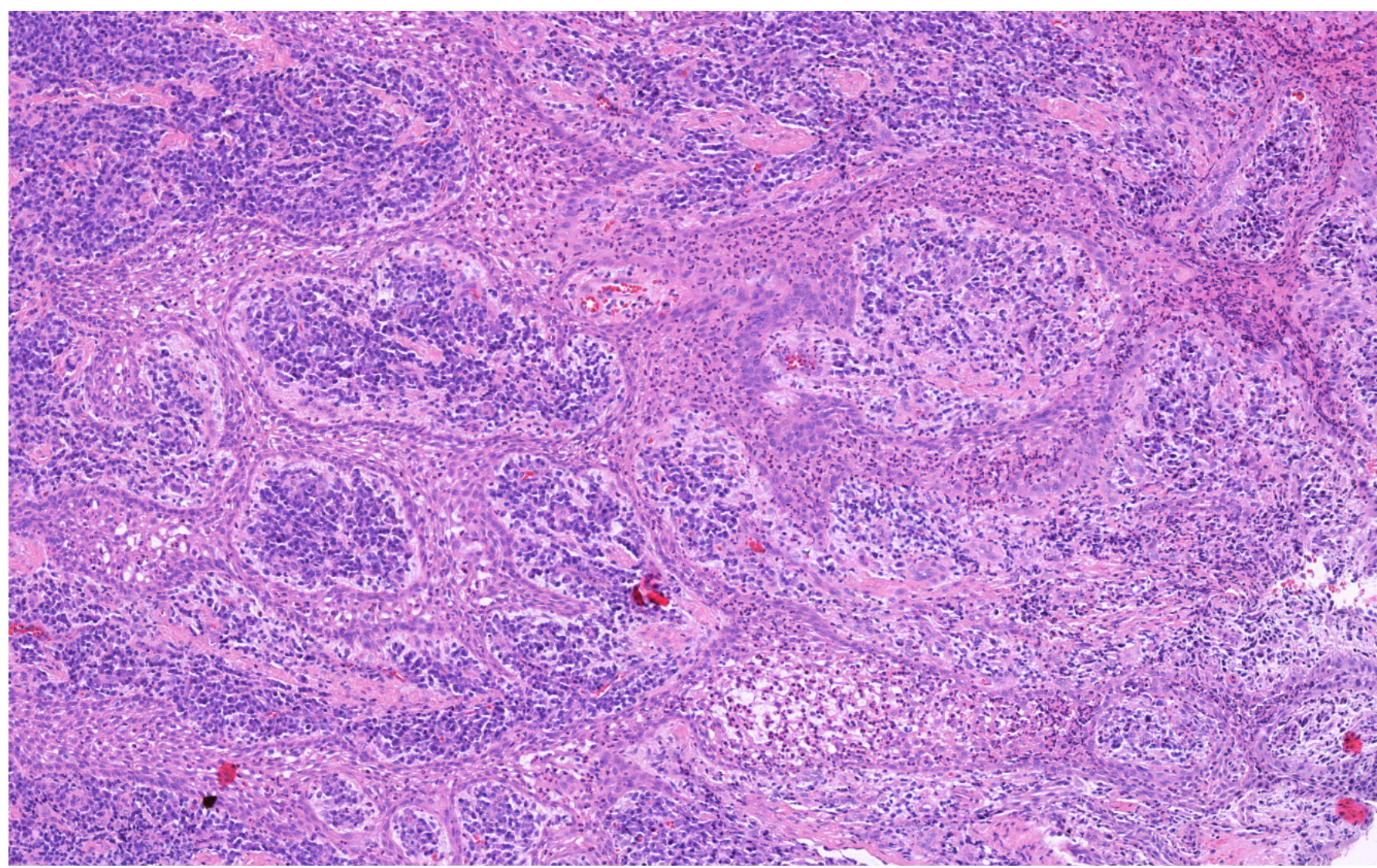

Fig. 6. Diffuse polymorphous inflammatory infiltrate (gingival biopsy from diabetic HE stain, 20x). 
Our data suggest an important role of increased TNF- $\alpha$ and IL- 6 concentrations regarding the progression of pathologic phenomena that characterise periodontal disease in diabetic subjects. The results sustain the utility of salivary immunologic examinations in case of periodontal disease, associated or not with different systemic conditions.

In our study, although no clinical signs of periodontal disease could be detected in diabetics, the microscopic changes of periodontal alterations were present. Our histological findings are in concordance with previously published data [23], and with those of other authors [24, 25], confirming the fact that hyperglycemia can induce alterations in periodontal structures, increasing the chance of periodontal disease occurrence [26-30]. Chronic hyperglycemia leads to irreversible complications such as neuropathy, retinopathy, nephropathy, cardiovascular and peripheral vascular diseases, delayed healing and periodontal diseases [1].

Periodontal diseases, including gingivitis (te reversible form), are highly prevalent in diabetic subjects. The changes that involve periodontal tissue alterations are mediated by the interaction between pathogens and the host immune-inflammatory response [31]. Periodontal pathogens are considered to be the initiative factor of the disease [32], but periodontal tissue destruction is the consequence of the host response to those pathogens [33]. It is still not fully elucidated by which exact mechanism diabetes affects periodontal tissue [34]. An altered immune-inflammatory response to bacterial pathogens has been suggested [33]. One means of investigating the local inflammatory status of the oral cavity is by analysis of saliva, a non-invasive approach for assessing the presence or absence of various inflammatory molecules.

In present study, increased salivary TNF- $\alpha$ and Il-6 levels were present in the same time with histological alterations in periodontal tissues, both in epithelium as well as connective tissue. Thus, we may confirm the hypothesis that immunological changes are involved in pathomechanism of periodontal disease in diabetic subjects.

Diabetic subjects included in our study had a history of at least 5 years of type 2 diabetes, with a poorely control glycaemic status, immunological and histological changes but no clinical signs of periodontal diesase. This might due to the fact that the main ethiological factor of periodontal disease (dental plaque) was absent, most of subjects mentaining a wery good oral hygiene. In this case, we conclude that type 2 diabetes can only co-induce periodontal breakdown through alteration of immune-inflammatory response to bacterial pathogens.

The clinical relevance of our study is that salivary detection of inflammatory cytokines can be a predictive tool for the development of periodontitis in diabetic subjects.

Limitations of the study are the small sample of subjects and the limited number of cytokines. Further research should include pro-inflammatory as well as anti-inflammatory cytokines, in order to get a more appropriate image about the complex immunological mechanism involved in periodontal breakdown in diabetics.

Further prospective studies are warranted to produce sufficient evidence to support the application of specific salivary biomarkers for prediction and prognosis of periodontal disease among patientswith diabetes.

\section{Conclusions}

The serum and mainly the saliva of patients with diabetes mellitus -without signs of periodontal idease- contained increased levels of TNF- $\alpha$ and IL-6, confirming the hypothesis of immunological implication, as a correlation between diabetes mellitus and periodontal disease. Histological alterations, suggesting a local inflammatory state, were present in periodontal tissue od diabetics, confirming the above hypothesis. The study reveals that saliva analysis is a quite efficient method in testing the periodontal breakdown progression in the subjects with T2DM.

\section{Acknowledgements}

The authors thank Assoc. Prof. Dr. Nagy Elod (Department of Biochemistry, UMF Tg.Mures) for statistic analysis and Dr.Mezei Tibor (Lecturer, Department of Morphopatology, UMF Tg.Mures) for histological analysis . The present study was conducted under the framework of the research grant no.1064/26.01.2015 financed by SC COSAMEXT SRL Tg.Mureş and developed by the University of Medicine and Pharmacy Tg.Mureş.

\section{Conflict of interest}

None to declare.

\section{References}

1. Sima C, Glogauer M. Diabetes mellitus and periodontal diseases. Curr Diab Rep. 2013; 13(3): 445-52.

2. Hanes PJ, Krishna R. Characteristics of inflammation common to both diabetes and periodontitis: are predictive diagnosis and targeted preventive measures possible? The EPMA journal. 2010; 1(1): 101-16.

3. 12. Taylor JJ, Preshaw PM, Lalla E. A review of the evidence for pathogenic mechanisms that may link periodontitis and diabetes. J Periodontol. 2013; 84(4 Suppl): S113-134

4. Monea A, Gruber R, Nagy E, Beresescu G, Moldovn C, Monea M. Saliva and serum levels of TNF-alpha and IL-6 in a sample of Romanian adult subjects with Type 2 diabetes mellitus and periodontal disease. European Scientific Journal.2014; 10: 350-359.

5. Gursoy UK, Kononen E, V.-J. Uitto et al., "Salivary interleukin-1 $\beta$ concentration and the presence ofmultiple pathogens in periodontitis," Journal of Clinical Periodontology, 2009; 36(11): 922-927.

6. Mirrielees J, Crofford LJ, Lin Y et al., "Rheumatoid arthritis and salivary biomarkers of periodontal disease," Journal of Clinical Periodontology, 2010; 37(12): 1068-1074.

7. Rathnayake N, Akerman S, Klinge B et al., "Salivary biomarkers of oral health: a cross-sectional study," Journal of Clinical Periodontology, 2013; 40(2): 140-147.

8. Ebersole JL, Schuster JL, Stevens J et al., "Patterns of salivary analytes provide diagnostic capacity for distinguishing chronic adult periodontitis from health," Journal of Clinical Immunology,2013; 33(1): 271-279.

9. Teles RP, Likhari V, Socransky SS, and Haffajee AD. "Salivary cytokine levels in subjects with chronic periodontitis and in periodontally healthy individuals: a cross-sectional study,"Journal of Periodontal Research, 2009; 44(3): 411-417.

10. Ramseier CA, Kinney JS, Herr AE et al. "Identification of pathogen and host-response markers correlated with periodontal disease," Journal of Periodontology, 2009; 80(3): 436-446. 
11. Aurer A, Jorgi'c-Srdjak K, Plančcak D, Stavljeni'c-Rukavina A, and AurerKǒzelj J. "Proinflammatory factors in saliva as possiblemarkers for periodontal disease," Collegium Antropologicum, 2005: 29(2): 435-439.

12. Frodge BD, Ebersole JL, Kryscio RJ, Thomas MV, and Miller CS. "Bone remodeling biomarkers of periodontal diseasein saliva," Journal of Periodontology, 2008; 79(10): 1913-1919.

13. Taba Jr. M, Costa PP, Trevisan GL; et al. "Salivary interleukin-6, matrix metalloproteinase-8, and osteoprotegerin in patients with periodontitis and diabetes," Journal of Periodontology, 2010; 81(3): 384-391.

14. Prakasam $S$ and Srinivasan M. "Evaluation of salivary biomarker profiles following non-surgical management of chronic periodontitis," Oral Diseases, 2014; 20(2) :171-7..

15. Ng, P.Y., et al., Candidate salivary biomarkers associated with alveolar bone loss: cross-sectional and in vitro studies. FEMS Immunol Med Microbiol, 2007; 49(2): 252-60.

16. Frodge, B.D., et al., Bone remodeling biomarkers of periodontal disease in saliva. J Periodontol, 2008; 79(10): 1913-1919.

17. Coman M,L., Immunological research in periodontal disease, PhD Thesis, Department of Odontology and Periodontology. 2009, University of Medicine and Pharmacy: Tg.Mures, Romania.

18. Baum BJ, Yates JR 3rd., Srivastava S, Wong DT, and Melvin JE. "Scientific frontiers: emerging technologies for salivary diagnostics," Advances in dental research, 2011; 23(4): 360-368.

19. Goodson JM. "Gingival crevice fluid flow," Periodontology 2000; 31:4354.

20. Wong DT. "Salivary diagnostics powered by nanotechnologies, proteomics and genomics," Journal of the American Dental Association, 2006; 137(3): 313-321.

21. Mandel ID. "Salivary diagnosis: more than a lick and a promise," The Journal of the American Dental Association, 1993; 124(1): 85-87.

22. Hu S, Li Y, Wang J et al. "Human saliva proteome and transcriptome," Journal of Dental Research, 2006; 85(12): 1129-1133.

23. Monea A, Mezei T, and Monea M. "The influence of diabetes mellitus on periodontal tissues: a histological study.” Rom J Morphol Embryol 2012; 5(3): 491-495.

24. Dağ, A., et al. "Morphological Changes Caused by Streptozotocin-
Induced Diabetes in the Healthy Gingiva of Rats." Experimental and clinical endocrinology \& diabetes: official journal, German Society of Endocrinology [and] German Diabetes Association, 2016; 124(03): 167-172.

25. Popescu, M. R., et al. "Histological Analysis of Collagen Fibers in Patients with Diabetes Mellitus and Periodontal Disease." Journal of Cytology \& Histology 2014; S4:2.

26. Silva JA, Lorencini M, Reis JR, Carvalho HF, Cagnon VH, StachMachado DR. „The influence of type I diabetes mellitus in periodontal disease induced changes of the gingival epithelium and connective tissue" Tissue Cell. 2008; 40: 283-292.

27. Hillman G, Dogan S, Guertsen W. "Histopathological investigation of gingival tissue from patients with rapidly progressive periodontitis". J Periodontol, 1998; 69(2): 195-208.

28. Brownlee M, Cerami A, Vlassara $H$. „Advanced glycosilation endproducts in tissue and biochemical basis of diabetic complications". N Engl J Med 1998; 318: 1315-20.

29. Bucala R, Makita Z, Koschinsky T, Cerami A, Vlassara H. ,Lipid advanced glycosylation: pathway for lipid oxidation in vivo". Proc Natl Acad Sci U S A 1993; 90: 6434-8.

30. Schmidt A, Weidman E, Lall E, et al. „Advanced glycation end-products (AGEs) induce oxidant stress in the gingiva: a potential mechanism underlying accelerated periodontal disease associated with diabetes". J Periodontal Res 1996; 31: 508-15.

31. Preshaw PM, Taylor JJ. ,How has research into cytokine interactions and their role in driving immune responses impacted our understanding of periodontitis?' J Clin Periodontol. 2011; 38(11): 60-84.

32. Kornman KS. "Mapping the pathogenesis of periodontitis: a new look”. J Periodontol. 2008; 79(8 Suppl): 1560-8.

33. Hanes PJ, Krishna R. „Characteristics of inflammation common to both diabetes and periodontitis: are predictive diagnosis and targeted preventive measures possible?"The EPMA journal. 2010; 1(1): 101-16.

34. Taylor JJ, Preshaw PM, Lalla E. ,A review of the evidence for pathogenic mechanisms that may link periodontitis and diabetes." J Periodontol. 2013; 84(4 Suppl): S113-134. 